Est Ag 47 (2012) 273-300

\title{
Los catecismos de Trento editados en Medina del Campo (1577-1604)
}

\author{
LUIS RESINES LLORENTE*
}

RESUMEN: El Catecismo del Concilio de Trento apareció en 1566. Tras ser vetada su edición en España por la Inquisición, y al no prosperar tampoco la traducción española, unos años después aparecieron seis ediciones del Catecismo de Trento que vieron la luz en Medina. Tres constituyen una primera serie sobre una edición alemana (1577-1583); las otras tres, constituyen otra serie, que reproduce un ejemplar de Lyon (1593-1604). En Medina del Campo hubo quien vio la posibilidad de hacer negocio con esta obra aún no difundida en España.

PALABRAS CLAVE: Catecismo, Trento, Medina del Campo, imprenta.

ABSTRACT: The Catechism of the Council of Trent was born in 1566. After the prohibition by Inquisition to be edited in Spain, and too translated to spanish, some year later six editions publisched it in Medina del Campo. Three of them make a serie from a german edition (1577-1583); the other three make up another serie from a french book of Lyon (1593-1604). In Medina del Campo there were who see the posibility of business with this book yet not diffused in Spain.

KEY WORDS: Catechism, Trent, Medina del Campo, printing.

*E-mail: lurello1@gmail.com

Instituto T. Agustiniano. Valladolid. 


\section{El fabuloso invento de la imprenta}

Cuando toda la escritura se llevaba a cabo a mano, los amanuenses (de ahí les viene el nombre) o escribientes tenían que emplear largas horas en llenar con rapidez y diligencia, a la vez que con limpieza, planas enteras. Pero como toda labor está sometida a la inevitable fatiga y a los fallos humanos, no son raros los tropiezos que se perciben en la lectura de manuscritos:

- era frecuente que se saltaran una línea, o que repitieran otra. Se explica porque si una misma palabra aparecía en líneas cercanas, era fácil saltar la vista de una a otra;

- era fácil escribir con irregularidad, de manera que cuando otro leyera lo escrito, confundiera una letra por otra, o una palabra por otra, entendiendo mal lo que se quería decir;

- eran inevitables las confusiones de letras, o de palabras, que hacían que el texto perdiera sentido, o se corrompiera.

Éstos y otros muchos defectos acompañaban (y siguen acompañando) a toda escritura realizada manualmente. Para cada uno, su propia letra es perfecta e inteligible, pero cuando es otro quien tiene que leerla, el lector no siempre está de acuerdo con el escritor.

$\mathrm{Si}$ a eso añadimos que en bastantes ocasiones el amanuense se limitaba a copiar otro texto que tenía delante, pero de cuya materia no entendía nada, se comprende perfectamente que hubiera toda clases de errores y fallos, porque escribía lo que le parecía que estaba escrito, pero en ocasiones sin saber si lo que ponía estaba bien o mal.

La llegada de la imprenta hizo que las cosas cambiaran de una forma increíble. Hoy, con los medios de que disponemos, tenemos que hacer un esfuerzo de imaginación para sospechar lo que pudo suponer semejante cambio.

La imprenta de tipos móviles -el invento de Gutenberg-hacía posible que en el texto impreso no se percibiera el cansancio del operario, porque una vez colocada cada letra en su lugar correspondiente, la página salía perfecta. Se evitaban los errores producidos por la fatiga. Pero aparecían otros, como era colocar las letras en distinto orden, lo que provocaba la necesidad de corregir. No era lo mismo poner "pato" que "tapo", aunque la corrección permitía remediar lo que en la escritura manual era irremediable (a no ser que se volviera a escribir de nuevo). 
Pero la gran ventaja, sin duda, era que, una vez compuesta la página (o las páginas), se podían realizar de forma rápida y barata un buen número de copias, en tanto que la escritura a mano requería empezar de nuevo. Por eso, la invención de Gutenberg tuvo tanto éxito y tan rápida difusión, puesto que todas las personas cultas que sabían leer captaron en seguida que aquello permitía abaratar los libros y agilizar su difusión. Y surgió la profesión de impresor, que muy pronto conoció un enorme éxito.

\section{Los libros impresos}

Tan gran difusión encontró el terreno abonado, porque la cultura reclamaba en aquellos momentos un retorno al pasado, a la recuperación de lo mejor de las manifestaciones culturales que se había extinguido, pero cuyas obras se conservaban manuscritas en buen número. En seguida se hicieron muy abundantes copias de las literaturas griega y romana. Y el nuevo estilo de pensamiento, determinado por el humanismo, encontró en la imprenta el soporte valioso para una expansión de los criterios y modos de pensar de cuantos se lanzaron con pasión a componer libros.

Los impresos anteriores a 1500 , los incunables, dan fe de la enorme producción de libros y de toda clase de impresos (incluso breves notas) que se difundieron merced al nuevo invento. Con posterioridad a dicha fecha, la cantidad de impresos crece de forma casi inabarcable: siempre aparecen nuevos impresos, a pesar de los muchos estudios y trabajos que se han hecho para detectar y seguir la pista de cuanto salió de las prensas en una determinada localidad.

Se imprimieron toda clase de libros: científicos, poéticos, religiosos, clásicos, amatorios, geográficos,... La lista sería demasiado larga. Y entre los libros religiosos, un género que tuvo una enorme difusión fue el de los catecismos, al que se podría añadir el de los libros de uso litúrgico, que hasta entonces habían de servirse de manuscritos. Hay varios catecismos incunables, y a lo largo del siglo XVI la cantidad de textos conocidos desbordan todas las previsiones para intentar hacer una lista. Hasta el punto de que para entonces ya son excepcionales los catecismos manuscritos.

\section{La imprenta como defensa de las ideas}

Como en el primer tercio del siglo XVI, en la cristiana Europa estalló el conflicto protestante, todos los que tenían algo que decir, todos los que 
estaban a uno u otro lado de la contienda, acudieron con celeridad a la imprenta a fin de difundir sus criterios no sólo con rapidez, sino además con la mayor extensión posible, pues con ello ganaban adeptos para su causa. Y como el conflicto religioso degeneró en pocos años en un conflicto multilateral, tanto católicos, como luteranos, tanto calvinistas como anglicanos o reformados inundaron las imprentas con sus propuestas.

Junto a los grandes tratados de índole teológica, estuvo asegurada la difusión de catecismos pequeños, breves manuales, escritos que se pudieran leer con no demasiado esfuerzo, que no resultaran muy caros por el escaso número de hojas, y que contuvieran lo básico del pensamiento de cada tendencia. Cada corriente tendía a expresarse de esta forma sencilla para llegar así al pueblo sencillo y ganar adeptos. Los catecismos dejaron de ser transmisores de la fe cristiana, sin otro adjetivo, puesto que de forma multitudinaria surgieron catecismos católicos, o catecismos luteranos, o catecismos calvinistas. Lo de menos era en qué lugar surgían, puesto que todos emplearon los mismos procedimientos. La lengua en que estaban redactados solía ser la lengua popular, a fin de que llegara a los más posibles. (Sólo los que estaban reservados a personas cultas se hicieron en latín).

De esta forma, si se sumaran los catecismos originarios del siglo XVI, surgidos en las diversas corrientes cristianas que entonces se separaron y distanciaron entre sí, en las diversas lenguas y procedencias, no sería difícil llegar a una cifra que rondara o estuviera muy cerca de los 1.000 catecismos diversos. $\mathrm{Y}$ es evidente que no es una cantidad ni un esfuerzo creativo como para desdeñarlo sin más.

La enorme sacudida que suscitaron las intervenciones de Martín Lutero hizo que surgieran multitud de catecismos, que tenían una doble finalidad: a la vez que la difundir la fe cristiana (como si nada se hubiera alterado), es evidente el fin propagandístico de dar a entender que la única manera adecuada de captar la fe cristiana era conforme a los patrones de quien firmaba el catecismo. Las tendencias e interpretaciones de los diversos grupos cristianos fueron inevitables.

Hubo, no obstante, gente hábil, como es el caso de Lutero o de Calvino, quienes en sus catecismos más breves, apenas incluyen enseñanza alguna que pudiera ser polémica, o suscitara recelos o rechazo en los lectores. Es preciso detectar los criterios de lo que enseñan más por sus silencios que por lo que aparece escrito. Voy a proponer un ejemplo. El burgalés Francisco de Enzinas, convertido al calvinismo, publicó el catecismo menor de Calvino, pero con muy numerosas adiciones suyas. Cuando aborda la materia de los sacramentos y se debe centrar en el número de los mismos, escribe entre ingenuo y documentado un párrafo que no tiene desperdicio, 
para que nadie eche de menos el resto de los sacramentos a los que estaba habituado, y se quede únicamente con los dos que acepta la fe calvinista:

«Quanto al número de los Sacramentos, hallo entre hombres doctos graues questiones y controuersias. Y no es nuestra opinión difinirlas en el presente tractado. Y pues que con todo studio procuramos de no salir de compendio, trataremos aquí solamente dos sacramentos que sin controuersia son mas excellentes y necessarios» 1 .

El propio Calvino, en su catecismo intermedio (de los tres que escribió), rehúye la polémica, y se limita a la afirmación simple, como si lo que enseña no pudiera ser objeto de debate:

«Maestro. - ¿Quántos Sacramentos ay en la Yglesia Christiana? / Discípulo.- No ay más de dos, que el Señor Iesu Christo instituyó comunes para toda la compañía de fieles»².

Algo semejante se podría decir de otros reformadores, pero son suficientes estos ejemplos para comprobar que resultaba más rentable no entablar polémica con la gente sencilla, sino hacer afirmaciones simples, a las que pudieran adherirse sin demasiada discusión ni demasiada dificultad.

Esto refuerza la idea de la utilización propagandística de los catecismos a fin de difundir los propios criterios y ganar adeptos para la causa respectiva. Hay una constatación contemporánea -no exenta de un tono de lamento- por el hecho de comprobar que el empleo de los catecismos impresos ha sido uno de los más poderosos medios de penetración de las ideas reformadas. Es la queja un tanto tardía, que se incluye en la introducción o prefacio del catecismo que en 1566 se publicó como fruto del concilio de Trento, cuando dice:

«...Porque aquellos que se propusieron inficionar las almas de los fieles, conociendo que en manera alguna podían hablar en público con todos, e infundir en sus oídos las venenosas voces, se valieron de otro ardid, por el qual derramaron los errores de la impiedad mucho más fácil y dilatadamente, porque además de muchos abultados libros con que procuraron trastornar la fe católica (de los quales fue fácil precaverse, por contener heregías manifiestas), escribieron también innumerables libri-

1 FRANCISCO DE ENZINAS Breve y compendiosa institución de la religión Christiana..., Topeia, Adamo Corvo, 1540 [pero Ginebra, Jean Crispin, 1542], 97r-v.

2 JuAn Calvino, Catecismo que significa forma de instrución..., s.l., s.i. [pero Ginebra, Jean Crispin], 1549, 122. 
llos al parecer piadosos, con los quales es increíble quán fácilmente engañaron las ánimas incautas de los simples» ${ }^{3}$.

De esta forma, sencilla, llegamos a hablar del catecismo que se decidió redactar en el concilio de Trento, como expresión de la fe católica.

\section{El concilio de Trento}

Es una total ingenuidad suponer que hasta que no se celebró el concilio tridentino no hubo reacción por parte de los católicos a las publicáciones reformadas de catecismos. Las hubo, y muchas. Es cierto que variaron de un país a otro, porque las cosas se percibían de diversa manera y con distinta intensidad y cercanía, dependiendo de dónde se viviera.

En la Alemania en que vivía Lutero, la reacción católica resultó inmediata, y fuertemente defensiva de los criterios católicos, como resultado de los ataques e invectivas marcadamente señalados de Lutero y sus seguidores. En Ginebra osciló, dependiendo de las alternancias en que Calvino controló la ciudad, o se alejó de ella, o de nuevo se hizo con los mandos de una manera excluyente. Inglaterra también sufrió las vaivenes políticos de la presencia en el trono de personas con criterios anglicanos o católicos, lo que produjo una situación y una mentalidad carente de la más mínima serenidad. En la Italia de los Estados Pontificios el control era notablemente católico; en España, primero con Carlos V y después con Felipe II, la decantación por la ortodoxia católica rechazó cualquier planteamiento que no coincidiera con ella; otro tanto se podría decir del resto de los países de Europa.

Católicos y no católicos se lanzaron a la empresa editorial, con una abundancia de catecismos increíble. Muchos de éstos han pasado a la historia como catecismos que disponen de un amplio respaldo y un elevado número de ediciones, bien por el carácter fundante de una tradición propia (en el caso de las iglesias reformadas), bien por el hecho de erigirse en baluarte del catolicismo.

La necesidad de convocar un concilio que abordase los temas objeto de litigio se sentía por parte de algunos católicos con más premura que por parte de quien debía convocar el concilio, el papa, disperso en cuestiones

3 CATECismo del santo concilio de Trento para los párrocos... Madrid, Ramón Ruiz, 1791, $4^{\mathrm{a}}$ ed., prólogo (p. 3). 
cortesanas, y menos atento a la marcha de la Iglesia. León X había tenido necesidad de ser arropado y empujado para pronunciar la excomunión a Lutero; Adriano VI emprendió una reforma frente a la corrupción de costumbres romanas, pero su muerte impidió otros pasos previsibles; su sucesor, Clemente VII acordó con Carlos V la celebración de un concilio que nunca llegó a convocar. Por fin, Paulo III anunció y convocó un concilio para 1536, que no se llegó a reunir; una nueva convocatoria para reunirse en Venecia en 1538 concluyó en fracaso, pues sólo acudieron 5 obispos; por fin, una tercera convocatoria, en Trento, reunió al concilio en el primer período de 1545 a 1547, hasta que la epidemia de peste en Trento, forzó el acuerdo de su traslado a Bolonia. El segundo período de nuevo en Trento, tuvo lugar en el papado de Julio III; y finalmente, el tercer período, hasta la clausura, se llevó a cabo entre 1562 y 1563, bajo el pontificado de Pío IV. Desde la Bula Exurge Domine de la excomunión de Lutero (diciembre de 1520) había transcurrido 43 años hasta la conclusión del concilio de Trento: lenta reacción que no había impedido la expansión de las diversas reformas al margen de la Iglesia católica.

\section{El catecismo del concilio}

El concilio de Trento, a lo largo de sus deliberaciones, había entrevisto la necesidad de hacer una proposición suficientemente cimentada de la legítima fe católica, como para que sirviera de base para la formación de los párrocos, y, por medio de ellos para la predicación a fin de que se hiciera presente ante los mismos fieles. Salvadas las excepciones, el nivel medio de formación de los sacerdotes dejaba mucho que desear, y gran parte de ellos se encontraban en pésimas condiciones para formar a los demás, puesto que tenían que emprender antes su propia formación.

Ya antes de que el concilio se trasladara a Bolonia, en la tercera sesión general, en la congregación general de 17 de marzo de 1546, se había pedido:

«Que se redacte un catecismo en lengua latina y vulgar, por varones sabios y piadosos, sacado de la propia escritura y de los padres ortodoxos",

y el cardenal de Jaén, Pedro Pacheco, dejó constancia de que se trataba de algo «necesario»; y el arzobispo de Bitonto, Cornelio Musso, insistía en que se hiciera el catecismo que tantas veces se había prometido. 
Se barajaron propuestas de hacer un catecismo sencillo en lengua vulgar, de amplia difusión para el pueblo; y otro más amplio y mayor fundamentación doctrinal, latino, para los sacerdotes. Sin embargo, el devenir de los acontecimientos hizo que se abandonara la idea de un texto sencillo para el pueblo. Cuando se publique el texto que finalmente se aprobó, en el prefacio aparecen las contradictorias palabras ya reproducidas sobre la difusión de las doctrina reformadas por medio de catecismos breves y sencillos; pero semejante queja y constatación no figura en el encabezamiento de un libro sencillo y apto para ser distribuido entre el pueblo, sino de un denso volumen que a cualquier persona de escasa formación se le caía de las manos. La decisión, tal como terminó por ejecutarse, es gravemente inconsecuente con lo que debería haberse hecho, porque se redactó un denso catecismo para los párrocos, y nada se hizo directamente para el pueblo fiel.

Hay que llegar al tercer período conciliar, para que se empiecen a dar pasos efectivos, se nombre una comisión -que inicialmente resultó inoperante-, y que se encomendaran redacciones parciales a algunas personas, a fin de dar pasos para su consecución. Pero a la hora de la clausura del concilio, el catecismo -como ocurrió con el breviario y con el misal- no era más que un proyecto repetidamente anhelado. En el decreto De reformatione, se incluyó el canon Ut fidelis (aprobado el 2 de noviembre de 1563), según el cual tanto obispos como párrocos debían enseñar al pueblo; tal predicación se realizará «según la forma establecida por el propio concilio para cada uno de los sacramentos en la catequesis» («iuxta formam a sancta synodo in catechesi singulis sacramentis praescribendam»).

Esta «forma» de que se habla, puede entenderse y traducirse en términos coloquiales, pues en estas palabras, se habla propiamente de «catequesis»; pero en realidad ha de entenderse no como una acción que se lleva a cabo, sino como un objeto que se utiliza, un catecismo, es decir, como libro que facilitara la formación de los curas.

La catequesis es una acción llevada a cabo por el catequista, ante uno o varios catequizandos en un período de tiempo mayor o menor; por el contrario, el catecismo es entendido como un libro, como un instrumento, empleđdo por el catequista, en el que se contienen aquellos elementos de la fe que ha de comunicar a través de sus propias palabras y con la acomodación suficiente para que llegue a ser percibido por los catequizandos. Es claro que aquí se está hablando de un libro, pues el texto añade a continuación que los obispos se encargarán de traducirlo fielmente a la lengua vulgar, para que sea eficaz ante los fieles. El concilio llegó hasta este punto; y 
la comisión conciliar redactora que se nombró no llegó a concluir sus trabajos a la hora de la clausura conciliar.

Estos trabajos previos fueron entregados a la curia romana, y cuando accedió al papado Pío V, en 1566, una de sus preocupaciones fue la creación de una comisión que trabajara en el proyecto, usando -quizá- alguno de los materiales anteriores, pero con la voluntad decidida de llevar a cabo el encargo conciliar. Los trabajos previos que se venían haciendo se intensificaron, y los miembros de la comisión, fueron rematando una notable labor de redacción de un libro que respondiera a las expectativas, y que además se adecuara a los criterios y necesidades para las que estaba previsto. Sin embargo, siempre trabajaron en la idea de un texto amplio, destinado a suplir la ignorancia de los sacerdotes, y se olvidó enteramente la posibilidad de un libro fácil para que pudiera ponerse en manos del pueblo.

\section{Publicación oficial}

Tras no pocos esfuerzos, y con intervención de no pocas manos, se llegó, por fin, a la impresión del catecismo encargado por el concilio, pero promulgado como tarea posconciliar por Pío V en 1566. Su título exacto es Catechismus ex decreto concilii tridentini ad parochos Pii Quinti, Pont. Max., iussu editus, Romae, Paulo Manucio, 1566.

El papa Pío V y el arzobispo de Milán, Carlos Borromeo, estaban interesados vivamente en promover la reforma propuesta por el concilio de Trento; el catecismo era uno de los medios -como lo fueron también el breviario y el misal- y aunque no pasaba de mero instrumento material, no dejaba de estar impregnado de un estilo y unos criterios que llevaran adelante la pretendida renovación. Dicho de forma muy breve y condensada, frente a unos curas mayoritariamente ignorantes y escasamente preparados, se pretendía poner en sus manos un texto que sirviera para su formación personal, y, en consecuencia, para su actuación pastoral por medio de la predicación. De ahí que, como indica el título de la obra, los destinatarios directos de la misma son los párrocos (ad parochos). Si éstos lo utilizaban y se formaban, su actuación, sus intervenciones ante el pueblo a ellos confiado y sus predicaciones podrían revertir en el conjunto de los católi$\cos$, que se beneficiarían de una mejor capacitación profesional.

El 8 de octubre de 1566 el libro está impreso, y a punto de ser distribuido a los libreros romanos, los que venderían los primeros ejemplares a los interesados en la adquisición de la novedad editorial. Pero junto al interés en adquirirla, estaba también el interés papal en que se difundiera. 
Dicho interés no consistía en editar un libro de amplia difusión, cuanto en proporcionar al clero católico el instrumento que se había establecido en el concilio y que, a unos años de su clausura, veía definitivamente la luz.

En otoño de 1566 vieron la luz pública dos ediciones latinas en Roma (una en folio, y otra en $8^{\circ}$ ), más la traducción italiana. Ésta, por la proximidad geográfica, se había estado preparando en simultaneidad a los trabajos de redacción, a medida que se daban por definitivos, y de ahí que apareciera con tanta prontitud. El encargado de llevar a cabo la traducción italiana fue el dominico Alejo Figliucci.

A esta salida comercial, pronto siguieron numerosas ediciones, que aparecieron en los años inmediatamente sucesivos en los más variados lugares; las numerosas ediciones certifican que en diversos países existía un suficiente número de personas interesadas en hacerse con un ejemplar, y dar comienzo así a una de las aplicaciones conciliares más profundas e inmediatas. Me estoy refiriendo a ediciones latinas, de las que aparecieron hasta 27 publicaciones en los diez años que siguieron a su primera edición. Pero, además, el papa Pío V estaba vivamente preocupado por la mayor y mejor difusión de este catecismo, y a instancias suyas se encargaron con celeridad traducciones.

\section{Traducciones}

Además de la versión italiana hecha por un dominico, se encargó a los jesuitas que realizaran la versión alemana, que fue ejecutada por Pablo Hoffaeus, y que se publicó en Dillingen en 1568. Igualmente se encargó a los jesuitas la traducción francesa; y el propio Pío $\mathrm{V}$ encargó al cardenal Estanislao Hosio que se responsabilizara de la traducción polaca. No todos los curas de estos países estaban capacitados para la lectura en latín; o para trasvasar los conceptos más notables a sus feligresías con garantías de solvencia.

Se hicieron traducciones en italiano, en francés, en alemán, en polaco. ¿Y en castellano? También hubo para España el doble encargo de la edición latina, y de la traducción correspondiente. El encargo de la edición latina (de 18 de abril de 1567) se quedó inoperante porque la quisquillosa Inquisición española veía pegas doctrinales en el texto latino aprobado y publicado por Roma, y no estaba dispuesta a permitir su publicación, si no intervenía en la corrección del texto; a esto el papa se negó tajantemente. Escasamente un mes después del encargo de la edición latina, llegó también de Roma en encargo de la traducción, y después de muchos dimes y diretes y de no pocas tensiones, a pesar de estar listo el texto traducido, de 
nuevo la Inquisición recomendó que no se llevara a la imprenta, y el propio Felipe II se reservó publicarlo o no, hasta que, finalmente el tema se relegó al olvido, ante otros asuntos que exigían respuestas inmediatas, y terminó olvidándose. Ni texto latino, ni versión castellana. Más papistas que el papa.

\section{Las ediciones latinas de Medina del Campo}

Existe un testimonio, datado en 1568 , que certifica que algunas personas, al menos, disponían del texto latino en España y habían tenido oportunidad de consultarlo. Se trata de lo que escribió y publicó en esa fecha el agustino Alonso de Orozco, en su Catecismo prouechoso, en el cual afirma sobre la insistencia en la oración:

«Esto nota mucho el Catecismo que Su Santidad ahora nos ha enviado de Roma hecho» 4 .

Privilegiadas manos, que tenían contactos con el extranjero, pudieron disponer de alguno de los ejemplares editados más allá de nuestras fronteras, y tuvieron oportunidad de consultar provechosamente la obra. Pero esto no era lo común.

Sin embargo, no había una excesiva dificultad, ni ésta resultaba del todo insuperable. Algunos ejemplares llegaron a tierra española. Y de nuevo es necesario acudir al insustituible papel comercial que desempeñaron las ferias de Medina del Campo. En ellas no estaban ausentes los libros, que eran trasladados buscando clientes desde los más diversos rincones europeos. La situación geográfica de Medina permitía la distribución de libros a las muy próximas universidades de Salamanca y Valladolid, así como a la un poco más distante de Alcalá de Henares; entre las tres copaban en aquellos momentos de esplendor lo más granado del pensamiento y de la cultura. Por consiguiente, hay que suponer que a Medina llegaron ejemplares de alguna de las ediciones europeas del Catecismo de Trento, fuera la procedencia que fuera. Otros habrían podido adquirirlo en viajes o por corresponsalía con personas que vivieran más allá de las fronteras.

Pero es preciso dar un paso más. Porque por encima de las suposiciones razonables, hay más que indicios de que en Medina había ejemplares

4 A. DE Orozco, Catecismo prouechoso..., Zaragoza, Juan Millán, 1568, "Exposición breve del padrenuestro". (Ver R. LAZCANO [ed.], AlONSO DE OROZCO. Obras completas. I. Obras castellanas (1), Madrid, BAC, 2001, 818). 
latinos del Catecismo de Trento. Y puesto que la edición española del texto latino se había frustrado como consecuencia de la suspicacia de la Inquisición española, ésta, sin embargo, no había llegado al extremo de prohibir que se importaran ejemplares, para que pudieran ser leídos y empleados en España. He señalado antes que existe constancia de 27 ediciones diversas de este catecismo publicadas en el extranjero en los diez primeros años de vigencia; 27 ediciones que podían proceder de Roma, de París, de Lyon, de Colonia o de Venecia... Y 27 ediciones procedentes de impresores foráneos que se embolsaban las ganancias legítimas de su producto.

No extraña, por tanto, que, a la vista de la circulación y demanda mantenida de la obra, alguno de los impresores, comerciantes y libreros afincados en Medina (o en sus cercanías) pensaran que resultaba igualmente legítimo editarlo por su cuenta y embolsarse las ganancias que de otra forma iban a parar a cajas ajenas.

\section{Dos series distintas de ediciones en Medina}

Pero al abordar la cuestión de las ediciones hechas en Medina del Campo no hay más remedio que hablar de dos series diversas de ediciones del Catecismo de Trento. Esto sólo es posible afirmarlo por medio del estudio de los ejemplares, y de la comparación con otros de procedencia extranjera, a partir de los cuales se hicieron las ediciones de Medina. No es posible asegurar, para cada una de las series, que los libreros e impresores que participaron en su realización y venta en Medina dispusieran de autorización comercial por parte de los editores de las ediciones extranjeras reproducidas; más bien me inclino a pensar que se limitaron en cada caso a plagiar el producto que iba a ser vendido, y que, con arreglo a la legislación vigente entonces en España, obtuvieran la correspondiente licencia civil para la impresión, así como la tasa que regulaba el precio de la venta y la preceptiva corrección de erratas efectuada antes de la tirada definitiva; estos extremos eran obligatorios y existían mecanismos para su cumplimiento y control. En cambio la autorización del editor alemán o francés, podía ser fácilmente evitada. Al fin y al cabo, el texto era el de un Catecismo hecho para toda la Iglesia católica; y como parte integrante de la misma Iglesia editaban lo que era su patrimonio doctrinal. Incluso hay más, puesto que las primeras ediciones de Medina, además de incluir la autorización papal exclusiva de edición al impresor Paulo Manucio, de Roma, también reproducen la autorización del virrey de Nápoles para editarlo en aquel territorio que formaba parte de la corona de Castilla, con la misma razón que lo era la tierra de Medina. 
Además, es preciso añadir que para aquellos primeros años, desde la aparición primitiva de Roma en 1566 , los productos que iban saliendo de los talleres de los diversos impresores, tenían una serie de pequeñas modificaciones, propias de cada edición o de cada impresor. Todos trataban de reproducir el texto auténtico, con la mayor fidelidad posible. Pero esto no impidió que se produjeran omisiones, añadidos en los marginales, adición de índices complementarios, corrección de erratas, introducción de notas,... Todo esto hacía que cada edición fuera en realidad igual, pero diferente.

Cuando se acometen las ediciones de Medina del Campo, la conciencia prevalente era que se editaba el mismo texto, que las ediciones eran iguales. Se carecía en aquellos momentos de un cotejo comparativo de las ediciones que se habían publicado en Roma, París, Lyon, Venecia, Colonia, Dillingen... para poder establecer las diferencias, depurar las enmiendas y mantener la absoluta fidelidad al texto primitivo. La conciencia de que se estaba editando el Catecismo que hacía unos años había aparecido en Roma, estaba por encima de las diferencias, estimadas como superficiales, o simplemente añadidos útiles para el uso habitual de la obra5. Los editores e impresores de Medina no tenían conciencia de estar arrebatando a nadie derechos exclusivos, sino prestando un servicio a la Iglesia española, ante la llegada lenta de ejemplares extranjeros.

\section{Primera serie de ediciones}

La primera serie está constituida por dos ejemplares editados en Medina, a los que hay que añadir, intercalándolo, otro que salió a la luz pública en Salamanca.

$N^{\circ}$ 1. Inaugura la serie primera este ejemplar:

Catechismus ex decreto Concilii Tridentini. Ad Parochos Pii Quinti Pont. Max. iussu editus, Methymnae Campi, expensis Benedicti Boyerii, 15776 .

5 Sin embargo, cuando se publica la segunda serie de ediciones de Medina del Campo, a partir de la edición de Guillermo Rovillio, de Lyon, de 1588, se reproduce en los ejemplares de Medina la carta de Rovillio a los párrocos de Lyon, en la que consta la preocupación de este editor francés por conseguir la edición más perfecta, a base de comparar y tomar elementos de otras ediciones consultadas y cotejadas por él.

6 C. PÉrez PAstor, La imprenta en Medina del Campo, Madrid, Suc. de Rivadeneyra, 1895 (ed. facsímil, Valladolid, Junta de Castilla y León, 1992), nº 180, p. 198-199. Ejemplar en la BNE R/27200. 
El mencionadó ejemplar, se hizo a expensas de Benito Boyer, por cuanto lo que este mercader y librero contemplaba era precisamente obtener ganancias; para ello no tuvo problema en realizar una inversión, que justifica que el libro esté impreso a su expensas («expensis Benedicti Boyerii»). Pero no consta por quién está impreso, qué imprenta contrató el librero afincado en Medina del Campo para llevar a cabo la edición. Es posible -pero no existe certeza- que el impresor fuera Francisco del Canto ${ }^{7}$, dada la estrecha vinculación entre él y el editor, Benito Boyer, como aparecerá en el ejemplar que se editó en tercer lugar. Es una mera conjetura, pues el impreso no da pistas del impresor, y sólo menciona al editor, que se permite incluir una dedicatoria, como en ocasiones hacían los impresores. Más aún, en portada aparece el escudo del mercader Benito Boyer, en lugar de la práctica que solía ser habitual de que fueran los impresores quienes incluyeran su propio escudo y su colofón.

Es un ejemplar en $8^{\circ}$, formato que resulta muy manejable; tiene 646 páginas en el cuerpo, más otras 16 introductorias y otras 15 conclusivas. En la introducción, aparece una especie de dedicatoria editorial, puesto que Benito Boyer no era el autor de la obra ni podía apropiarse del Catecismo cuya procedencia era de todos conocida; esa dedicatoria editorial la dirige el mercader y librero a Diego de Covarrubias y Leyva. Éste había sido nombrado presidente del Consejo de Castilla (1572), y a la sazón era obispo de Segovia; en septiembre de 1577 -año de la edición- había sido nombrado obispo de Cuenca, aunque falleció sin llegar a tomar posesión de esta ciudad. La dedicatoria, en cambio, le hace constar ya como obispo de Cuenca. Hombre de gran fama, particularmente como jurisconsulto, Benito Boyer estimó oportuno poner la obra bajo su amparo.

En la obra hay un dato que llama poderosamente la atención: la fecha de la licencia civil para proceder a la edición del libro es de Madrid a 26 de abril de 1575; está expedida a nombre de Benito Boyer, «mercader de

7 «Empezó a imprimir este notable tipógrafo en el año 1552, y terminó en 1590. Durante este largo período salieron de sus prensas gran número de obras (...) En algunas ocasiones se asoció con su hermano Mateo e imprimieron juntos en los años 1554 y 1555 (...) Además de esto imprimió muchas obras que costearon los libreros de Medina del Campo, Valladolid y Salamanca, y en especial Benito Boyer, cuyo escudo ponía en los libros que éste costeaba (...) Tenía la imprenta en la calle Ávila. De su matrimonio con Isabel Lozano tuvo tres hijos, Alonso, Francisco y Santiago del Canto. Este último le sucedió en la imprenta de Medina del Campo, y los dos primeros pasaron a Perú en 1586 para dedicarse al comercio de libros en aquel reino, para lo cual contaban con el apoyo de los cuantiosos libreros de Medina, que les remitieron grandes cantidades de libros para que allí los vendieran». (C. PÉrez PASTOR, o.c., 486-487). 
libros, vecino de Medina del Campo». Esto equivale a reconocer que, al menos dos años antes de la publicación, el librero había presentado el libro al Consejo de Castilla, pero anduvo titubeando si acometer o no la empresa. Dispuso de la licencia en esa fecha, pero alguna razón que se nos escapa frenó sus propósitos editoriales, puesto que componer e imprimir un libro que ya estaba escrito no podía llevar tanto tiempo.

La aparición pública del libro hubo de ser posterior al 6 de septiembre de 1577 , en que el dedicatario de la edición, Covarrubias, fue nombrado obispo de Cuenca, y consiguientemente trasladado de sede, pues en la dedicatoria figura ya como obispo de Cuenca; y hubo de ser anterior al 27 de septiembre de 1577, pues en esa fecha falleció en Segovia, sin llegar a tomar posesión del nuevo obispado, y la dedicatoria no se modificó en última instancia al momento de sacarlo a la luz. Benito Boyer estuvo en posesión de la licencia desde finales de abril de 1575 y la llevó a efecto en la segunda mitad de 1577 , sin que lleguemos a saber qué pudo ocasionar tal dilación.

Entre los preliminares, Boyer se apoya y reproduce el privilegio papal de Pío V al impresor romano Paulo Manucio para imprimir en exclusiva el catecismo durante cinco años; para la fecha de edición de Medina (1577), habían caducado de sobra esos cinco años $(1566+5=1571)$, pero el privilegio papal suponía un aval que legitimaba la edición y nada le costaba reproducirlo. Además reproduce el privilegio para el Reino de Nápoles, concedido por el virrey Perafán de Ribera ${ }^{8}$, concedido en Nápoles el 31 de mayo de 1566 («Neapoli, die ultimo mensis Maij M. D. LXVI.»). No deja de ser curiosa y llamativa la fecha de la concesión de este privilegio, cuando la edición primera del Catecismo, todavía no había sido publicada en Roma; hay que deducir que la expectación creada por la inminente aparición de la obra movió los resortes para su difusión y que nadie pudiera tachar de falta de interés a las autoridades correspondientes.

A continuación del texto propiamente dicho, sigue un índice de todo lo que era digno de ser señalado a lo largo de las páginas del Catecismo ( «Index eorum quae in hoc Tridentinae synodi Catechismo annotatu digna visa sunt»).

8 Perafán de Rivera corresponde a Per(o) Enriquez Afán de Rivera, virrey de Nápoles desde el 12 de junio de 1559 hasta su fallecimiento el 2 de abril de 1571. Una contracción del nombre con el apellido Afán da como resultado la denominación Perafán, mantenida como identificadora de su familia. 
Es precisamente toda esta serie de preliminares y complementos, además del cotejo del texto propiamente dicho con sus peculiaridades, lo que da la pista para poder asegurar con absoluta certeza que la edición de Medina (además de las otras dos que constituyen esta primera serie), es reproducción fiel y exacta de la edición de Colonia, Arnold Birckman, 1573; esta edición, a su vez, estaba en directa relación con la que se publicó en Colonia, Gervino Calenio, 1572. Los cambios de preliminares obedecen a las circunstancias particulares de cada edición, pero el texto, sus variantes, su composición, sus marginales evidencian una dependencia inequívoca.

En otras palabras, el mercader Benito Boyer importa ejemplares alemanes del Catecismo de Trento, y comprueba que la demanda es lo bastante sólida como para emprender una edición. Para ello no hace más esfuerzo que pasar a reproducir un ejemplar de los importados, tras obtener la licencia del Consejo de Castilla; el comerciante y editor Benito Boyer pasa a la acción, y pone la edición bajo la tutela del dedicatario, Diego de Covarrubias, presidente del poderoso Consejo de Castilla. De esta forma ve la luz la primera edición latina impresa en España del Catecismo de Trento. Medina del Campo, la comercial Medina, es su cuna.

Parece indispensable, por la relevancia que tuvo en la publicación de las tres primeras ediciones, reunir unos datos en torno a la persona de Benito Boyer. No era impresor, sino mercader ${ }^{9}$. Desde su Lyon natal, se vino a Medina, donde se estableció y casó con Beatriz Delgado del Canto, hija de Mateo del Canto y de Catalina Delgado ${ }^{10}$. Poniendo un poco de orden en los apuntes dispersos en torno a su persona, proporcionados principalmente por Pérez Pastor y por Ruiz Fidalgo, hay que situarle como «uno de los más ricos libreros de Medina del Campo, y el primero atendiendo al número de obras cuya impresión costeó. En 1557 había en Lyon un librero llamado Jacobo Boyer (...) Supuesto el parentesco entre ambos [Jacques y Benoit Boyer] y el deseo de ensanchar su esfera de acción en el comercio de libros, escogieron la plaza de Medina, y a este fin vino Benito

9 J. Delgado Casado. Diccionario de impresores españoles, Madrid Arco/Libros, 1996, 116-118 se apoya en los datos de PÉrEz PASTOR, para plasmar un retrato de Benito Boyer, del que dice que colaboró en ediciones con Francisco del Canto; en algunos de esos impresos ejecutados entre ambos aparece impreso el escudo de Benito Boyer, lo que «ha llevado a algunos a suponer que era del propio impresor», cuando no era así. Un motivo de tan estrecha colaboración estriba en que estaban emparentados, pues Benito Boyer estaba casado con la sobrina de Francisco del Canto.

10 Además de lo señalado en la nota anterior, los datos que siguen sobre Benito Boyer son una recopilación de lo que ofrece C. PÉrez PASTOR, La imprenta en Medina, 495, y L. RuIz FIDALGO, La imprenta en Salamanca. 1501-1600, 142-143. 
Boyer a establecer en dicha villa», afirma Pérez Pastor. Aunque no hay fecha aproximada de nacimiento, ni tampoco de su venida a Medina, la información complementaria aportada por Ruiz Fidalgo, le señala como «librero francés, cuya familia estaba establecida en Lyon como libreros. Junto a su hermano Jacques, viene a Salamanca». Este Jacques puede ser muy probablemente hijo, como Benito, del librero lionés Jacques Boyer, a quien Pérez Pastor castellaniza el nombre como Jacobo.

Los dos hermanos se trasladaron con la intención de ampliar el negocio, y a la vez, disponer, tanto en España, como en Lyon, de una corresponsalía para estar al tanto de lo que se imprimía en el otro país. Pero inicialmente se establecieron en Salamanca, y no en Medina, información que Pérez Pastor desconoce. Hay un rasgo importante por su entidad, aunque resulte desconocido en los detalles: «por problemas con la Inquisición, [Benito] se tiene que volver a Lyon, quedando Jacques como imprimidor en casa de Andrea de Portonariis». No hay forma de saber qué dificultad pudo tener con la Inquisición, pero parece obvio que tuvo que ser algo que expresó, en forma oral o impresa, y que reflejaba su propio pensamiento, pues de otra forma, si se trataba de alguno de los libros que financió, la responsabilidad ante el Santo Oficio sería no del librero-editor, sino del autor.

En 1562 -lo que parece indicar que no debió tratarse de una ausencia prolongada- volvió a España y abrió librería en Medina del Campo; no en Salamanca, pero es claro que la distancia no era tan grande como para eludir la acción de la Inquisición, si existía alguna causa pendiente. Allí, desde Medina, estableció relaciones comerciales con el resto de Castilla y con la América española. Ya está indicado que fue el librero de mayor capacidad económica de su tiempo, y Ruiz Fidalgo aporta como razón el inventario de su librería, realizado en 1592, al momento de su muerte.

«Empezó a editar el año 1562 y continuó sin interrupción hasta el año 1589; y no siendo bastante su actividad y medios la imprenta de Medina, buscó impresores en otras poblaciones, especialmente en Salamanca, donde, a sus expensas, se hicieron casi más impresiones que en la misma Medina»11. Por su parte, Ruiz Fidalgo señala la fecha del inicio de esta actividad tan notable en 1566; cuatro años de diferencia. Pero en palabras de ambos bibliógrafos, destacan su actividad conjunta en Medina y en Salamanca. Pérez Pastor acompaña además una información nada desdeñable cuando indica que «examinando las encuadernaciones de las obras de Soto [Domingo de Soto], se ve que en casi todos los ejemplares existentes, que son muchos, la piel, sus adornos, manezuelas, etc. son idénticas, demostran-

11 C. PÉrez PASTOR, 495. 
do que se dispusieron a la venta encuadernadas; pero siendo dicha venta exclusiva de Benito Boyer, debe suponerse que tenía un gran taller de encuadernación, cuya suposición comprueba la uniformidad en los precios de encuadernación que se ponen a los libros que se detallan como encuadernados en el inventario de sus bienes»12. Que cesara su actividad en 1589, y que falleciera en 1592 parece hablar con claridad de una enfermedad que le apartó de los negocios. Los mantuvo su hijo Luis Boyer. Pero también hay constancia de un «Joan Boyer, mercader de libros» quien intervino en obras impresas en Valladolid el año 1583, a lo que hay que añadir la información local, pues el mismo Juan Boyer financia diez años después, en 1593, otra obra impresa en Valladolid, y en esta ocasión se hace constar «Juan Boyer, mercader de libros en Medina del Campo». Esto indica que, además de su hijo Luis, otro Boyer, Juan, -quizá hijo de Jacques, pues no interviene en las cuentas entre la viuda y Luis, hijo de Benito- se dedica también a la actividad financiera de libros todavía en vida de Benito, y la continúa cuando éste ya ha fallecido; y lo hace precisamente desde Medina ${ }^{13}$.

$\mathrm{N}^{\text {o }}$ 2. La edición de Salamanca tiene el mismo título que la anterior de Medina 14 :

Catechismus ex decreto Concilii Tridentini. Ad Parochos Pii Quinti Pont. Max. iussu editus, Salmanticae, ex officina Ildefonsi a Terranova y Neyla, 158015 .

12 A propósito del inventario de su librería, V. BÉCARES - A. LuIS IgLESIAS, La librería de Benito Boyer. Medina del Campo, 1592. PÉREZ PASTOR, o.c., 456-462 publica parcialmente una relación del inventario de sus bienes, en las cuentas hechas entre su viuda Beatriz Delgado y su hijo Luis Boyer.

${ }^{13} \mathrm{La}$ información sobre Juan Boyer, en M. ALCOCER Y MARTíneZ, Catálogo razonado de obras impresas en Valladolid. 1481-1800, Valladolid, Casa Social Católica, 1926 (ed. facsímil, Valladolid, Junta de Castilla y León, 1993), n 303, 304 y 345, en dos obras diversas de Alejo de Venegas, para los dos primeros números señalados y para otra obra de Francisco Arias, en el último número indicado, impresas todas ellas en Valladolid por Diego Fernández de Córdoba.

14 Ejemplar en la BNE R/22815.

15 J. DELGADo CASADo, o.c., 673 indica que el impresor estuvo activo en Salamanca entre 1577 y 1585 . Era hijo de Juan de Terranova y María de Neyla, y sucedió en la imprenta a Juan Bautista Terranova. Este Juan Bautista Terranova era tío de Ildefonso; el que un hermano se llamara Juan y el otro Juan Bautista favorece la confusión. «Juan María Terranova es librero e impresor en Medina y Salamanca, y desde 1553 se encuentran ediciones costeadas por él y [Jacomé] Liarcari en Medina, pero la casa de Salamanca 
Como buen comerciante, Benito Boyer estuvo atento a lo que pasaba en la culta Salamanca, y tres años después de la edición de Medina del Campo, publicó otra en Salamanca, que se ha impreso en la de Ildefonso (o Alonso) de Terranova y Neila. Desde los criterios comerciales se entiende que tras la edición de Medina, la que publicó y vendió a continuación aparezca impresa en Salamanca, a la búsqueda de la rentabilidad.

Es exactamente igual que la edición anterior de Medina, en $8^{\circ}$, con el mismo número de páginas, más las preliminares y el índice complementario, y de la misma forma que su precedente, también incluye la dedicatoria que el librero Boyer dirige a Diego de Covarrubias, sin cambio alguno. La única diferencia notable es que la licencia real para la impresión está expedida a nombre de «Pedro Madrigal, impresor de libros, vecino de la ciudad de Salamanca»; tiene fecha de Madrid, a 17 de enero de 1579. En dicha licencia real, se condensa el título con la breve expresión de «libro intitulado Catechismus ad Parochos», en latín, mientras que para la edición anterior la licencia lo identificaba como «un libro intitulado el Catechismo del Papa Pío Quinto». Otra leve discrepancia respecto a la edición anterior de Medina es que en lugar de incluir en portada el grabado de Benito Boyer, aparece una xilografía de santo Domingo; pero es claro que la edición está impulsada por Benito Boyer, cuya dedicatoria elimina todas las dudas posibles. Pero se reproducen sin variación tanto el Motu proprio de Pío V, como la autorización de Perafán de Ribera, fechada en Nápoles el 31 de mayo de 1566.

continúa, pues en los libros del claustro de la Universidad, del año 1550, aparece una nota que dice: "Item, en este dicho claustro se vio una petición de Juan María de Terranova, librero, que vive en la tienda nueva del Cantón del Hospital, en casas de la Universidad..."». [El librero solicita al claustro una vivienda mejor]. «Unido con Liarcari imprime en Medina, donde a la vez tenía editorial, y en la misma forma lo hace en Salamanca desde 1557 , pero a partir del 60 , ya lo hace solo, utilizando cinco marcas a base de la flor de lis, que caracteriza a los de su país, y con la leyenda "Sub timore Sanctissimi nominis tui laboramus"». Juan María de Terranova era «mercader de libros, florentino, habitante en estos reynos de España» (Ver L. Cuesta GuTIÉRReZ, La imprenta en Salamanca, Salamanca, Ed. Universidad, 1960, 48-49; V. Beltrán DE Heredia, Domingo de Soto. Estudio biográfico documentado, Salamanca, San Esteban, 1960, 520). De su matrimonio, tuvo un hijo, Alonso, y dos hijas. Este Alonso es el que editó el Catecismo en Salamanca. Su nombre latinizado (Ildefonsus), induce a una cierta confusión, pues en castellano lo percibimos como nombre distinto. «Utiliza varias formas para denominarse: Alonso de Terranova y Neyla, o Alonso de Neyla. Se hace cargo de la imprenta al desaparecer su familiar Juan Bautista. Sigue con la tradición familiar en cuanto a los libros que imprime: las ediciones de Soto financiadas unas por los Portonariis, otras por el librero salmantino Juan Moreno y otras por el librero de Medina Benito Boyer, cuando éste consigue la exclusiva de la edición de sus obras». (L. RuIZ Fidalgo, La imprenta en Salamanca. 1501-1600, Madrid, Arco/Libros, 1994, 105). 
Al término del último índice, un escueto «Finis» precede al colofón del impresor: «Salmanticae. Ex officina Ildephonsi a Terranova y Neyla. 1580».

Los tres años de distancia entre la edición primera de Medina, y la siguiente de Salamanca permiten pensar que la primera se había agotado, y que es la demanda de ejemplares lo que lleva a realizar una nueva impresión. Que esta vez la edición se hiciera en Salamanca permite entrar en escena al impresor y librero salmantino Pedro Madrigal, interesado en la venta de ejemplares; sin embargo no fue él quien llevó a cabo la impresión, sino Alonso de Terranova. El cambio de lugar de impresión no ha de llevar a la conclusión de que en cada ciudad se vendían respectivamente los ejemplares editados en ella, dada la escasa distancia temporal entre ediciones, y la cercanía entre Medina y Salamanca.

$N^{\circ}$ 3. La tercera edición de esta serie sacada a luz por el librero Boyer tiene exactamente el mismo título:

Catechismus ex decreto Concilii Tridentini. Ad Parochos Pii Quinti Pont. Max. iussu editus, Methymnae, Excudebat Franciscus a Canto; expensis Benedicti Boyerii, 1583.

Transcurridos otros tres años desde la publicación salmantina, de nuevo Benito Boyer editó el mismo Catecismo, y para ello consta que contrató al impresor de Medina Francisco del Canto. Cambia el lugar, y el impresor, respecto a la edición anterior, salmantina, pero nada más. Ya tenía el modelo, y lo único que hizo fue ajustarse a él escrupulosamente. Aparece con claridad que el impresor es Francisco del Canto, y que el editor-librero que abona los gastos y después comercializa la edición es Benito Boyer ${ }^{16}$. En el caso de esta edición tercera de la serie, la licencia de impresión está expedida a nombre de Francisco del Canto «impressor de libros y vezino de la villa de Medina del Campo» (Madrid, 14 de diciembre de 1580 , es decir, el mismo año en que salía a la luz la edición de Salamanca, segunda de esta serie financiada por Benito Boyer). Pero nada se altera en las páginas preliminares ${ }^{17}$, ni en las de texto propiamente dicho, ni en las complementarias consagradas al índice.

16 C. PÉREZ PASTOR, nº 198, p. 232.

${ }^{17}$ Figura el privilegio del Virrey de Nápoles, D. Perafán de Rivera, que es el mismo y con la misma fecha que figuraba en la primera edición de esta serie, la de 1577 , pues, expedido para quince años, aún estaba en vigor. PÉREZ PASTOR, p. 232-233, reproduce el 
Son, por consiguiente, tres ejemplares calcados: calcados uno de otro, y -salvo la carta dedicatoria y la preceptiva licencia-calcados también de las ediciones que había realizado en Colonia el impresor Gervino Calenio. Se trata, fundamentalmente, de una operación comercial para editar el Catecismo en España, ya que nadie se había decidido a hacerlo, y obtener con ello unos beneficios que, de otra forma, marcharían en parte al impresor alemán. Para entonces, la Inquisición se había despreocupado de introducir apostillas y notas en el texto aprobado en Roma (para conseguir una más exquisita y depurada ortodoxia), y no puso dificultad alguna para la impresión, venta y difusión, dado que, en los años precedentes, se estaban difundiendo en España ejemplares del Catecismo impresos en el extranjero $\mathrm{y}$ transportados hasta Medina, como principal centro difusor.

\section{Segunda serie de ediciones}

La segunda serie de ediciones del Catecismo de Trento, aparecida en Medina supone un corte radical en todos los sentidos respecto a la primera. Podría parecer en un primer momento que únicamente se trataba de seguir editando el libro, replicando una edición a otra, y continuar vendiéndolo, en función de las peticiones. Pero no hay nada de eso.

texto del privilegio: «D. Perafanus de Ribera, Dux de Alcala \& in hoc regno praedictae Maiestatis Vicerex, Locum tenens \& capitaneus generalis, \&c. Magnifico viro Paulo Manutio regio fideli dilecto gratiam regiam \& bonam voluntatem. Quum pero suam Sanctitatem, ut fuit nobis expositum, tibi commisum \& injunctum fuerit, ut expensis populi Romani Catechismum, novum Breviarium, seu Missale \& alios libros novos imprimi cures: supplicatumque propterea nobis foret pro tui parte, quatenus regiae \& catholicae Majestatis nomine tibi concederemus per alliquot temporis spatium, videlicet, per annos quindecim, libros praedictos \& quoscumque alios novos necnon complures in melius redactos, aut cum novis commentariis, declarationibus, seu postillis, vel traductos in latinum seu vulgare eloquium, seu in quamcumque linguam, impressos tamen in Urbe sub nomine Populi Romani, in praesenti Regno imprimi non posse, nec extra Urbem impressos in regnum inmitti, nec alio modo exemplari \& quovis modo imprimi facere, \& in regno praedito vendi, vel quovis modo contractari nisi tantummodo vel per te, vel per tuos haeredes \& successores ac alios tui vel tuorum haeredum praedictorum parte, dicto tempore annorum quindecim perdurante, Nos tua attenta causa praedicta \& quod super hac concessione fuimus suae Sanctitatis nomine requesiti, ea propter tenore praesentium de certa nostra scientia, deliberate \& consulto ac ex gratia speciali, praedictae Majestatis nomine, cum deliberatione \& assistentia Regii Collateralis Consilii, statuimus \& decernimus quod per annos quindecim die data praesentium in ante numerandos nemini liceat in hoc Regno libros per iam dictos imprimere, aut exemplari \& imprimi facere, nec extra dictam Urbem impressos in hoc praedictum Regnum inmittere aut aliquo pacto contractare absque speciali permissione praedicti Pauli Manutii vel dictorum suorum haeredum \& successorum dicto tempore annorum quindecim perdurante». 
Esta serie se inaugura con la edición de 1593, pero para esa fecha Benito Boyer había muerto ya ${ }^{18}$. Le sucedió al frente del negocio su hijo Luis, pero éste no tuvo la misma visión comercial o el mismo arrojo a la hora de emprender una edición, de manera que, aunque continuó en Medina (donde también trabajaba Juan Boyer, sobrino de Benito y primo de Luis, entre 1583 y 1599) no continuó la línea de editor-librero que había seguido su padre. También para 1593 había fallecido el impresor que intervino en la última edición de la serie anterior, Francisco del Canto ${ }^{19}$.

En consecuencia, otro impresor, Santiago del Canto, que había sucedido a su padre Francisco en la imprenta que éste tenía en Medina ${ }^{20}$, realizó una edición del catecismo que provenía de Trento; era el año 1593, y habían transcurrido diez años desde la última edición de Boyer, por lo que es más que probable que se hubiera agotado y los ejemplares ya no se encontraran.

$\mathrm{N}^{\mathrm{o}}$ 4. A la vista de esto, Santiago del Canto inauguró la segunda serie de tres ediciones de esta obra con la siguiente publicación:

CATECHISMUs ex decreto sacrosancti Concilii Tridentini, iussu Pii Quinti Pont. Max. editus. Nunc primum in capite, sectionesque distinctus, variisque Patrum sententiis et auctoritatibus munitus. Accessere duo indices, quorum alter docet: qua ratione ea quae in hoc opere traduntur, ad Euangelia Dominicalia, et aliorum aliquot festorum, possint accomodari, alter rerum est longe iis locupletior et ordinatior qui hactenus editi sunt, Methymnae Campi, apud Iacobum a Canto, Expensiis Ambrosii du Port, 159321.

18 Ha aparecido ya que falleció en 1592, (o finales de 1591), pues las particiones de los bienes inventariados entre su viuda y su hijo Luis tienen fecha de enero de 1592 .

19 La suposición, en palabras de DELGADo CASADo es que debió morir en 1590 o poco después; desde luego antes de 1593, porque para entonces existe constancia documental de contratos en que figura su viuda (J. DELGADo CASADo, o.c., 116-118).

20 Santiago del Canto aparece como impresor; participó en el negocio de seguir editando el catecismo, agotadas las ediciones anteriores. Él personalmente imprimió dos de las tres ediciones de esta segunda serie, pero no pudo continuar la labor emprendida, puesto que «murió a principios de 1597, empobrecido y minado por las deudas, según palabras de Rubio González, y ese año ya imprime su madre, la viuda de Francisco del Canto», quien estuvo activa únicamente los años 1597-1598. (J. DELGADo CASADO, o.c., 119).

21 C. PÉrez PASTOR, n 224, p. 265-266 cambia un poco el título: Catechismus ex decreto Concilii Tridentini. Ad parochos Pii Quinti Pont. Max. iussu editus. Nunc primum in capite, sectionesque distinctus, variisque Patrum sententiis et auctoritatibus munitus. Accessere duo indices, quorum alter docet: qua ratione ea quae in hoc opere traduntur, ad Euangelia Dominicalia, et aliorum aliquot festorum, possint accomodari, alter rerum est 
No hay más que comparar el título, para apreciar que se incorporan notables cambios en el impreso. El cambio -o los cambios, si se prefiereresulta importante, aunque no afecta al texto, sino a los complementos del mismo, que hacían que la edición resultara más útil, y, por lo mismo, digna de ser adquirida.

Pero son muchas más las cosas que es preciso anotar. En primer lugar, que la tasa de la edición (a tres maravedís por pliego), se expide en Madrid el 25 de septiembre de 1593, al librero Antonio Manuel, del que parece que no se encuentra rastro en Medina, sino en Madrid. Pero aún es preciso retroceder algo más, porque la licencia de impresión, destinada al librero Antonio Manuel, también expedida en Madrid, data de cuatro años antes, del 22 de diciembre de 1589. Además, dicha licencia a este librero es licencia para «reimprimir» este libro. Pero no está claro si el mismo librero había hecho alguna otra edición, y por tanto reimprimiría la obra; o si, como ya habían salido otras ediciones del Catecismo, aunque fuera a costa de otro librero, ahora se «reimprime», pues no es una obra absolutamente desconocida.

Para complicar algo más los datos sobre este ejemplar, a continuación del impresor, Santiago del Canto, consta esta anotación: «Expensis Ambrosii de Port»: a expensas de Ambrosio du Port. Éste era un librero de origen francés -como también lo fuera Benito Boyer-, establecido en Medina, y que hizo buena amistad con su colega y compatriota, pues colaboraron en varias ocasiones. La suposición que parece más verosímil es que el librero Antonio Manuel había obtenido en Madrid la licencia para imprimir la obra, y que pudo negociar con Ambrosio du Port (o Duport) las condiciones de la edición: el editor francés la sufragaba y el librero madrileño buscaba la salida comercial. Parece que así encajan mejor los datos, por la constatación que figura en la siguiente edición de Medina: en los términos comerciales hoy empleados, a Antonio Manuel se le adjudica al papel de librero, y a Ambrosio du Port el de editor; éste sería finalmente quien,

longe iis locupletior et ordinatior qui hactenus editi sunt, Methymnae Campi, apud Iacobum a Canto, Expensiis Ambrosii du Port, 1593. (= «Catecismo por decreto del Concilio Tridentino. Destinado a los párrocos por orden de Pío Quinto, Pontífice Máximo. Ahora dispuesto por primera vez en capítulos y secciones, y acompañados de sentencias y autoridades de los Padres. Se han añadido dos índices, de los que el primero muestra de qué manera las enseñanzas que contiene esta obra pueden acomodarse a los evangelios de los domingos y de otras fiestas; el otro, sobre lo que contiene, es más amplio y está mejor ordenado que los que hasta ahora se han editado»). Pero el título exacto es como figura arriba. Ejemplares: Bibl. Pública Toledo, Fondo Antiguo 16.703 y 3160. 
actuando en consecuencia con la legítima licencia de Antonio Manuel, financió y llevó a cabo la edición del Catecismo que Santiago del Canto imprimió en Medina.

Pero no sería esto lo más importante, puesto que, abandonando completamente el modelo seguido hasta ahora de la edición de Gervino Calenio, hecha en Colonia en 1572, el nuevo modelo que se sigue es otro: el de Guillermo Rovilio o Rovillio, en la edición hecha por este impresor en Lyon, en 1588. A nuevo librero y nuevo editor, nuevo modelo a seguir.

En consecuencia, no aparece ni la dedicatoria de Benito Boyer a Diego de Covarrubias y Leyva, ni los preliminares de la edición alemana que había servido de punto de partida para las ediciones de la primera serie. La presente edición medinense calca los preliminares de la edición lionesa de Guillermo Rovillio.

La nueva edición medinense, también en $8^{\circ}$, tiene 453 páginas, más 24 de preliminares y otras 27 finales de complementos. En las páginas preliminares, además de la tasa y licencia aludidas, aparece la carta que el impresor lionés dirige a los párrocos, con la que abre su edición. Él había editado con anterioridad el mismo Catecismo, igualmente en Lyon (1567, 1568 y 1569); pero en 1588 se propuso llevar a cabo una edición renovada, que mantuviera el texto propiamente dicho, pero que mejorara y facilitara su uso para los párrocos.

«Guillermo Rovillio dice en su dedicatoria que después de compulsadas las ediciones de Venecia por Manucio, Burdeos por Millanges y de Amberes por Plantino, y viendo que en la primera había que enmendar el contexto, en la segunda el índice de los Evangelios y en la tercera la división de capítulos y secciones, encargó a personas competentes dichas correcciones, con objeto de que la edición que preparaba fuera la más correcta de todas» 22 .

Es muy posible que cuando llegó a Medina algún ejemplar de esta edición lionesa, remozada en los complementos al Catecismo, apareciera abiertamente ventajosa respecto a las ediciones medinenses que había circulado desde 1577 hasta 1583. La consecuencia es que se abandonó el modelo anterior, y se repitió, -igualmente calcada- la edición lionesa de 1588. Tampoco hay que excluir enteramente que el comerciante Ambrosio Du Port estuviera al tanto de las ventajas de la edición que efectuó Rovillio en Lyon, y que se hiciera traer intencionadamente algún ejemplar de la más útil publicación, dispuesto a reproducirla.

22 C. Pérez Pastor, nº 224, p. 267. 
Esta edición hecha en Medina tiene en las páginas preliminares el índice de los evangelios dominicales y festivos, y también aparece un índice de los capítulos y de las secciones del Catecismo; este índice constituía un importante y útil recurso para los párrocos. Sigue a continuación el texto del Catecismo propiamente dicho, que aparece dividido y articulado en capítulos y secciones dentro de cada capítulo, que facilitan su manejo; a esta división respondía el índice precedente. Además, cada una de esas secciones está introducida con un titulillo, en forma de pregunta, que es respondida con el párrafo o párrafos que siguen a continuación. Tras las páginas dedicadas al Catecismo, en las complementarias del final consta la bula de Pío IV que contiene la profesión de fe tridentina; y, por último, el índice de materias contenidas en la obra.

La edición de Medina aparece, pues, con unos preliminares propios y exclusivos de ella, más otros que proceden de la edición de Lyon.

$\mathrm{N}^{\circ}$ 5. La edición que sigue a la de 1593 es la que se efectuó también en Medina en 1596. Lleva el mismo largo título que la anterior, aunque se actualiza la fecha, y figura también como editor Ambrosio du Port. Se efectuó en 159623:

CATECHISMus ex decreto sacrosancti Concilii Tridentini, iussu Pii Quinti Pont. Max. editus. Nunc primum in capite, sectionesque distinctus, variisque Patrum sententiis et auctoritatibus munitus. Accessere duo indices, quorum alter docet: qua ratione ea quae in hoc opere traduntur, ad Euangelia Dominicalia, et aliorum aliquot festorum, possint accomodari, alter rerum est longe iis locupletior et ordinatior qui hactenus editi sunt, Methymnae Campi, apud Iacobum a Canto, Expensis Ambrosii du Port, 159624 .

Ya indiqué en la edición que antecede que había unos preliminares propios de la edición de Medina, más otros calcados de la edición de Lyon. Pues bien, en esta edición de 1596, entre los preliminares propios de la impresión medinense, consta de nuevo la tasa al librero Antonio Manuel (Madrid, 25 de septiembre de 1593) ${ }^{25}$, y la licencia al mismo librero

${ }^{23}$ Hay dos ejemplares en la BNE R/27257, que está completo, y R/29072, al que le falta la portada y la última página del índice final.

24 C. PÉrez PASTOR, $n^{\circ} 239$, p. 308-309 ofrece un título parecido, pero no exactamente igual, como ya había hecho con la edición anterior.

25 En el extracto del título con el que se identificaba la obra, la licencia habla de «un libro intitulado Catechismo de los Concilios, que con su licencia hizo imprimir Antonio 
(Madrid, 20 de agosto de 1594); pero la novedad, a la que aludí antes, y que permite sostener la colaboración entre impresor, editor y librero, es que en la licencia a Antonio Manuel consta que «havía hecho imprimir un libro intitulado el Catechismo Romano de Pío V, la cual dicha impresión se había acavado y avia mucha falta del dicho libro». Se mantiene, por tanto, la tasa y la fecha de la misma (25 de septiembre de 1593), pero se actualiza la licencia con una nueva concesión, pues la licencia para la edición de 1593 databa de 22 de diciembre de 1589 , en tanto que la licencia para esta nueva aparición es de 20 de agosto de 1594.

Esto también aporta una constatación comercial: editado en 1593 ( $\sin$ constancia del mes de aparición), a mitad del año siguiente, en agosto de 1594, ya se han agotado los ejemplares impresos y el librero Antonio Manuel se ve en la precisión de solicitar nueva autorización para volver a editarlo, puesto que la demanda de la obra es notable.

Entre los preliminares que no son originarios de la edición de Medina, figura la dedicatoria o carta, muy culta, del impresor de Lyon, Guillermo Rovillio a sus clientes inmediatos, los curas de la diócesis de Lyon. En consecuencia, el resto de los preliminares (el Index evangeliorum Dominicalium, el Index capitum et sectionum hujus operis = Índice de los evangelios dominicales e Índice de los capítulos y secciones de esta obra), el texto fundamental en sí mismo, la división del mismo texto y el índice final (Index in Catechismum iis longe copiosior, qui hactenus editi sunt = el índice del catecismo bastante más abundantes de los que se han editado hasta ahora) son idénticos, pues calcan fielmente la edición de Medina de 1593. Al final aparece un colofón que dice «Iesu Christo aeterno Deo aeternique Dei Filio laus et gloria (= Honor y gloria a Jesucristo, Dios eterno e hijo de Dios eterno).

$\mathrm{N}^{\mathrm{o}}$ 6. Todavía hay constancia de otra edición más, impresa en Medina del Campo, cuyos datos son ${ }^{26}$ :

CATEChismus ex decreto sacrosancti Concilii Tridentini, iussu Pii Quinti Pont. Max. editus. Nunc primum in capite, sectionesque distinctus, variisque Patrum sententiis et auctoritatibus munitus. Accessere duo indices, quorum alter docet: qua ratione ea quae in hoc opere traduntur, ad Euangelia Dominicalia, et aliorum aliquot festorum, possint accomodari, alter rerum est longe iis locupletior et ordinatior qui hactenus

Manuel, librero». Resulta curioso ese plural de «Catecismo de los Concilios», que no he visto empleado en ninguna otra ocasión.

26 Ejemplar en la BNE 8/16965. 
editi sunt, Methymnae Campi, apud Christophorus Lasso \& Franciscum Garcia, Expensis Ildephonsi Perez, 160427.

Era obligado incluir esta edición en la serie segunda, que clausura; la razón es que lo que se imprime, sin variaciones sustanciales, es el mismo texto que figuraba en las ediciones $4^{\mathrm{a}}$ y $5^{\mathrm{a}}$ : el ejemplar calcado de la edición de Guillermo Rovillio de 1588.

Aun siendo idéntico el texto y sus respectivos apéndices complementarios, son otras las personas que intervienen en esta sexta edición medinense. Los impresores son ahora Cristóbal Lasso (o de Lasso) y Francisco García. El editor que financia la tirada es Ildefonso Pérez. Y en los preliminares exclusivos de esta edición (no los que repite de la edición de Lyon, 1588) consta que la licencia para imprimirlo se otorga en Valladolid, a 22 de octubre de 1603, al librero Félix López. Es un nuevo trío de personas (o cuartero, pues aparecen dos nombres como impresores) el que está al frente de esta edición.

La sustitución de los impresores es entendible, puesto que Santiago del Canto, que había intervenido en las dos ediciones inmediatamente anteriores, estuvo activo entre los años 1592 y 1597, en que murió. Los impresores Cristóbal Lasso Vaca y Francisco García toman el revelo. Como sucedía en una especie de endogamia tipográfica, Cristóbal Lasso Vaca había emparentado con los miembros de la familia de impresores Del Canto, puesto que se había casado con María del Canto. Era familiar e impresor del Santo Oficio. Trabajó asociado con Francisco García en varios impresos conocidos. Rubio González supone que el verdadero impresor era Francisco García, y que Lasso Vaca era el dueño de la imprenta, además de diversificarse en otros negocios. En algunos de los impresos conjuntos, en el colofón sólo aparece el nombre de Lasso. Francisco García estuvo activo en Medina entre 1603 y 1608; estas fechas coinciden con la actividad de Cristóbal Lasso, que se fijan entre 1599 y 1608. Frảncisco García había empezado a trabajar en las tareas de imprenta en Valladolid como empleado de Adrián Ghemart; en torno al año 1580 se independizó para instalarse en Medina primero como librero, y pasar después a figurar como impresor, en la colaboración señalada con Cristóbal Lasso ${ }^{28}$.

El editor que financia la publicación es Ildefonso Pérez. Parece que no hay duda en identificarlo con Alfonso Pérez. De éste, consta que era

27 C. PÉREZ PASTOR n ${ }^{\circ} 268$, p. 354-355.

28 J. Delgado CASADo, o.c., 304 y 377. 
«mercader de libros. Se trasladó con la Corte, editando varias obras. También en Medina del Campo costeó el Catecismo del Concilio Tridentino. Después regresó a Madrid» ${ }^{29}$. El librero que obtiene la licencia y que está interesado en la venta del Catecismo es Félix López, quien la obtiene en Valladolid, a diferencia de lo que había sucedido en las dos ediciones anteriores en que se interesó por la venta el librero Antonio Manuel, presumiblemente instalado en Madrid.

Este trío (o cuarteto) de protagonistas de la última edición del Catecismo hecha en Medina del Campo no tuvieron especial problema en continuar editándolo tal como había sido publicado antes, en las dos últimas apariciones. La única diferencia es que, quizá por ahorrar unas páginas, aunque retocaron el título -como ha aparecido- no suprimieron de él la indicación de que el libro contenía un índice de las principales materias tratadas; pero tal índice no aparece en esta edición de Medina.

Seis ediciones del Catecismo de Trento que vieron la luz en Medina (al añadir la de Salamanca, respaldada por el mercader y librero Benito Boyer). Tres constituyen una primera serie, y se cimientan sobre una edición de procedencia alemana, que replican; las otras tres, constituyen otra serie independiente de la anterior, pues el ejemplar que tienen como partida es el que venía de Lyon.

${ }^{29}$ M. AlCocer y Martínez, Catálogo razonado de obras impresas en Valladolid. 1481-1800, Valladolid, Casa Social Católica, 1926, 787 (Ed. facsímil, Valladolid, Junta de Castilla y León, 1993). 